Jahangirnagar University J. Biol. Sci. 5(2): 15-26, 2016 (December)

\title{
Mass propagation of Bambusa bambos (L.) Voss through in vitro culture
}

\author{
Raihan I. Raju* and Shyamal K. Roy \\ Department of Botany, Jahangirnagar University, Savar, Dhaka-1342, Bangladesh
}

\begin{abstract}
Protocol for mass propagation of Bambusa bamboos (L.) Voss was developed through in vitro culture. Nodal segments containing pre-existing axillary bud, after surface sterilization, were inoculated on liquid Murashige and Skoog's (MS) basal medium containing different concentrations and combinations of cytokinins (BAP, TDZ and Kn). The highest direct shoot induction (90\%) was obtained in the MS liquid medium supplemented with $2.0 \mathrm{mg} / \mathrm{l} \mathrm{BAP}$ and $1.0 \mathrm{mg} / \mathrm{l} \mathrm{TDZ}$ with maximum average number of shoots $(3.14 \pm 0.06)$ per explant. Highest shoot multiplication (16.58 \pm 0.24 shoots per culture) with highest average shoot length $(9.21 \pm 0.13 \mathrm{~cm})$ was obtained when in vitro raised shoots were cultured in gelrite gelled MS medium in conjunction with $2.0 \mathrm{mg} / \mathrm{l} \mathrm{BAP}$ and $1.0 \mathrm{mg} / \mathrm{l} \mathrm{TDZ}$. Incorporation of $10 \%$ coconut water with $4 \%$ sucrose in the above mentioned medium resulted satisfactory shoot growth and development with an average $26.7 \pm 0.60$ shoots per culture. For root induction, in vitro raised shoots were divided into clumps of 4-5 shoots in each clump and transferred onto both liquid and gelled half-strength MS medium containing different concentrations and combinations of auxins (IBA and NAA). Maximum rooting (86.67\%) was achieved in half-strength of MS medium fortified with $2.5 \mathrm{mg} / \mathrm{l} \mathrm{IBA}$ and $2.5 \mathrm{mg} / \mathrm{l} \mathrm{NAA}$ with an average $8.72 \pm 0.42$ root per shoot. The rooted plantlets were then transferred to polybags containing garden soil, sand and compost mixture with 1:1:1 ratio. After a month the hardened plantlets were then transferred to the larger pots containing garden soil and compost with 1:1 ratio for sufficient growth and finally transplanted to the field. In this process, the highest $100 \%$ survivability was recorded from well-established rooted plantlets. The regenerated plants showed well developed root and shoot systems in field condition.
\end{abstract}

Key words: Bambusa bambos, mass propagation, in vitro culture.

\section{INTRODUCTION}

Bamboo is a giant grass which is one of the most fascinating and versatile group of plants known to mankind. These are long-lived, woody, evergreen, members of subfamily Bambusoideae of family Poaceae (Singh et al., 2012a). Most of the bamboos are shrub like, medium or dwarf with a few exceptions as a climber (Liese, 1987). It is the fastest growing plant on the planet with a growth rate of up to 1.2 meters a day. Its roots can reduce soil erosion by up to 75 percent. As bamboos are fast growing plants, recently they are considered as a prime renewable resource for biomass production (Sharma and Sarma, 2011).

There are about 75 genera and over 1250 species of bamboo in the world. Bamboo species occurring in Bangladesh were recorded as 27 in 10 genera in which Bambusa spp. are mostly common (Alam, 1992). Approximately 157 species from the genus Bambusa

\footnotetext{
* Corresponding author. E-mail: raihan1792@gmail.com
} 
were documented worldwide, in which the most widely used species is B. bambos (L.) Voss also known as 'Giant Thorny Bamboo' or 'Indian Thorny Bamboo' which is native to Southeast Asian country (Sharma et al., 2014). It prefers humid tropical climate, moist soil and grows along perennial rivers and valleys as well as in other moist sites.

Bambusa bambos is cultivated for building and scaffolding material. It is used as a raw material for pulp and paper industry. The spiny branches are used for fencing. It has been widely used in Indian folk medicine. In Ayurveda, the entire plant is used as astringent, laxative, for inflammatory conditions and as diuretic (Joshi, 2000). It may be used for reforestation and stabilization of eroding banks. It is often planted as wind-breaks and is recommended in agroforestry.

Current methods of bamboo propagation rely on culm cutting, rhizome division, offset cuttings, branch cuttings, air layering or seed (Prutpongse and Gavinlertvatana, 1992). Rhizome cutting and culm cuttings are the most widely used methods of vegetative propagation. There are number of problems with this type of propagation. The offsets used are bulky and heavy. Clumps are not always available due to seasonal specificity, so that large scale vegetative propagation is impossible (Saxena and Bhojwani, 1993). Because of the difficulties with these traditional propagation methods, in vitro methods of propagation (micropropagation) provides an alternative to meet the demand of the market, which allow the rapid multiplication of disease-free and true to type selected clones. In this study, an efficient and reproducible micropropagation protocol has been established mass production and generating uniform clones for the bamboo species, Bambusa bambos (L.) Voss.

\section{MATERIALS AND METHODS}

Nodal segments containing unsprouted axillary buds of Bambusa bambos (L.) Voss were collected from the lateral branches of young culm thicket grown in the campus of Jahangirnagar University, Savar, Dhaka. The nodes containing pre-existing axillary buds were used to initiate and establish the in vitro culture. Leaf sheath of nodal segments were removed with sharp blades and nodes containing lateral spines were removed by scraping carefully with scalpel. These nodal explants were thoroughly washed under running tap water to remove the dust particles. They were then washed with few drops of liquid detergent for 15 minutes followed by 3-4 times washing with distilled water. Further surface sterilization of the explants was done under laminar airflow by giving fungicide treatment (Bavistin) for 5-7 minutes followed by 3 times washing with autoclaved distilled water. Finally these explants were surface sterilized with $(0.05 \%, 0.1 \%$ and $0.2 \%) \mathrm{HgCl}_{2}$ solution for 3-10 minutes to ensure contamination free culture and then thoroughly washed with autoclaved distilled water.

Then both ends of the sterilized nodal segments were trimmed and cultured singly in liquid MS medium (Murashige and Skoog, 1962) supplemented with various concentrations and combinations of Cytokinins (BAP, TDZ and Kn). The $\mathrm{pH}$ of the medium was adjusted to 5.8 with the help of $\mathrm{pH}$ meter by adding $0.1 \mathrm{~N} \mathrm{NaOH}$ or $0.1 \mathrm{~N}$ $\mathrm{HCl}$ accordingly prior to autoclaving at $15 \mathrm{lbs}$ pressure and $121^{\circ} \mathrm{C}$ for 15 mins. Axillary 
buds of nodal segments were sprouted within 18-25 days. The sprouted buds were then sub-cultured in another bottle containing same gelled media. Within 4-weeks induced shoot elongated and developed into a number of multiple shoots. The elongated cluster (4/5 shoots) of shoots were used as explants for further shoot multiplication and root induction. At the end of each stage, shoot number per explant and shoot length $(\mathrm{cm})$ were calculated.

The effect of different concentrations of source (1-5\%) and coconut water $(5-20 \%)$ on shoot multiplication were also studied. An aseptic condition was maintained throughout the whole operation. Cultures were incubated at $24 \pm 2^{\circ} \mathrm{C}$ temperature under illumination with florescent light for 16-hours light and 8-hours dark per day.

In vitro induced shoots ( $4 / 5$ shoots) in multiplication medium were then used for root induction. Half-strength of both solid and liquid MS medium with various concentrations and combinations of IBA and NAA were used. After 30-45 days of culture, the number of roots per shoot cluster and rooting percentage was recorded. The plantlets with welldeveloped root system were acclimatized.

For acclimatization the plantlets with sufficient root inside the test tubes were kept in the room temperature for 5-7 days to bring them in contact of normal temperature. The roots of the plantlets were gently washed under running tap water to remove any chemical attached to the root area. Immediately after that they were transferred to small polybags containing the soil mixture garden soil, sand and compost with 1:1:1 ratio. The plants along with pots were covered with transparent polythene bags to prevent sudden desiccation. The inner side of the polythene bags was sprayed with water at every 8 hours to maintain high humidity around the plantlets. The polythene bags were gradually perforated to expose the plantlets to the outer normal environment and subsequently removed after 14 days.

\section{RESULTS AND DISCUSSION}

In the present investigation, nodal segments containing pre-existing axillary bud from mature clumps of Bambusa bambos were mainly preferred as explants due to their availability all the year round in sufficient numbers to initiate the in vitro cultures. Similarly Arya and Sharma, (1998); Nayak et al., (2010); Anand et al., (2013) and Brar, (2014) also used nodal segments as explant to initiate the in vitro cultures of B. bambos. Most suitable result on surface sterilization was obtained when nodal segments of $B$. bambos were surface sterilized with $0.2 \% \mathrm{HgCl}_{2}$ for $7 \mathrm{~min}$ which resulted in $92 \%$ contamination free explants (Table 1). The present results corroborates with the findings of Kheng and Lee, (2011) in B. ventricosa; Waikhom and Louis, (2014) in B. tulda and Melocanna baccifera; Sharma and Sarma, (2011) in B. balcooa; Jha et al. (2013) in Dendrocalamus hamiltonii; Arya and Arya, (2015) in D. asper, D. hamiltonii and Drepenostachyum falcatum. In the present investigation, for in vitro shoot induction MS medium was used. The use of MS basal medium for micropropagation of B. bambos has been reported in earlier reports (Arya and Sharma, 1998; Nayak et al., 2010; Anand et al., 2013 and Brar, 2014). 
Table 1. Effects of different concentrations of $\mathrm{HgCl}_{2}$ solution at different duration of time on surface sterilization of nodal explants of Bambusa bambos

\begin{tabular}{|c|c|c|c|}
\hline \multirow{3}{*}{$\begin{array}{l}\text { Duration of } \\
\text { treatment } \\
\text { (minutes) }\end{array}$} & \multicolumn{3}{|c|}{ Concentrations of $\mathrm{HgCl}_{2}$ solution } \\
\hline & $0.05 \%$ & $0.1 \%$ & $0.2 \%$ \\
\hline & $\begin{array}{l}\% \text { of contamination } \\
\text { free explants }\end{array}$ & $\begin{array}{l}\% \text { of contamination free } \\
\text { explants }\end{array}$ & $\begin{array}{l}\% \text { of contamination free } \\
\text { explants }\end{array}$ \\
\hline 03 & 0 & 10.00 & 60.00 \\
\hline 04 & 0 & 20.00 & 65.71 \\
\hline 05 & 0 & 28.89 & 82.22 \\
\hline 06 & 12.00 & 34.00 & 86.00 \\
\hline 07 & 16.00 & 52.00 & 92.00 \\
\hline 08 & 37.78 & 68.89 & $95.56^{*}$ \\
\hline 09 & 42.00 & 70.00 & $96.00 * *$ \\
\hline 10 & 45.00 & - & - \\
\hline
\end{tabular}

Different concentrations of BAP alone or in combination with TDZ and Kn have been used for direct shoot induction. But MS liquid medium supplemented with $2.0 \mathrm{mg} / \mathrm{l} \mathrm{BAP}$ and $1.0 \mathrm{mg} / \mathrm{l} \mathrm{TDZ}$ was found to be most effective for direct shoot induction. In this concentration $90 \%$ explants responded for shoot induction with an average $3.14 \pm 0.06$ shoots per explant after 18-25 days of inoculation (Table 2). Whereas Kabade, (2009) reported that MS liquid medium containing $0.1 \mathrm{mg} / \mathrm{l} \mathrm{NAA}$ and $0.25 \mathrm{mg} / \mathrm{l} \mathrm{TDZ}$ was the best for direct shoot induction (100\%) with an average 6.53 shoots per explants within 3 weeks in case of $B$. bambos. TDZ was found to be suitable in some other previous studies on D. strictus (Singh et al., 2000); B. edulis (Lin et al., 2004) and B. oldhamii (Lin et al., 2007). Arya and Sharma, (1998); Anand et al., (2013) and Nayak et al., (2010) investigated that the cytokinins (BAP and $\mathrm{Kn}$ ) were effective in direct shoot induction of the axillary buds of B. bambos as well as Devi and Sharma, (2009) in Arundinaria callosa, and Chaudhary et al., (2004) in D. strictus. BAP has also been found to be essential for direct shoot induction in bamboo (Nadgir et al., 1984; Banik, 1987 and Saxena, 1990).

Table 2. Effects of different concentrations and combinations of cytokinins in MS liquid medium on direct shoot induction from the nodal segments of Bambusa bambos

\begin{tabular}{c|c|c|c}
\hline $\begin{array}{c}\text { Cytokinins } \\
(\mathrm{mg} / \mathrm{l})\end{array}$ & $\begin{array}{c}\text { \% of responding } \\
\text { explant }\end{array}$ & $\begin{array}{c}\text { Average No. of shoots/ } \\
\text { explant }(\text { Mean } \pm \mathrm{SE} *)\end{array}$ & $\begin{array}{c}\text { Average shoot length } \\
(\mathrm{cm})(\text { Mean } \pm \mathrm{SE})^{*}\end{array}$ \\
\hline $\mathbf{B A P}$ & & & \\
0.5 & 13.33 & $1.09 \pm 0.12$ & $1.89 \pm 0.17$ \\
1.0 & 44.00 & $1.64 \pm 0.15$ & $2.03 \pm 0.41$ \\
2.0 & 73.33 & $2.63 \pm 0.31$ & $2.08 \pm 0.48$ \\
$\mathbf{B A P + T D Z}$ & & & \\
$1.0+0.5$ & 56.00 & $2.33 \pm 0.08$ & $2.00 \pm 0.06$ \\
$1.0+1.0$ & 80.00 & $2.87 \pm 0.21$ & $2.87 \pm 0.23$ \\
$2.0+0.5$ & 56.67 & $2.38 \pm 0.14$ & $2.17 \pm 0.15$ \\
$\mathbf{2 . 0 + 1 . 0}$ & $\mathbf{9 0 . 0 0}$ & $\mathbf{3 . 1 4} \pm \mathbf{0 . 0 6}$ & $\mathbf{3 . 4 3} \pm \mathbf{0 . 2 9}$ \\
$\mathbf{B A P + K n}$ & & & \\
$1.0+0.5$ & 36.00 & $1.49 \pm 0.25$ & $1.76 \pm 0.18$ \\
$1.0+1.0$ & 64.00 & $2.48 \pm 0.14$ & $2.34 \pm 0.36$ \\
\hline SE* $=$ Standard & & &
\end{tabular}


Table 3. Effects of different concentrations and combinations of Cytokinins (BAP, TDZ and Kn) and Auxin (NAA) on shoot multiplication of Bambusa bambos

\begin{tabular}{|c|c|c|c|}
\hline $\begin{array}{l}\text { Auxin/Cytokinin } \\
(\mathrm{mg} / \mathrm{l})\end{array}$ & $\begin{array}{l}\% \text { of culture } \\
\text { showed } \\
\text { proliferation }\end{array}$ & $\begin{array}{c}\text { Average No. of regenerated } \\
\text { shoots/culture } \\
\left(\text { Mean } \pm \mathrm{SE}^{*}\right)\end{array}$ & $\begin{array}{l}\text { Average shoot length } \\
(\mathrm{cm}) \\
\left(\text { Mean } \pm \mathrm{SE}^{*}\right)\end{array}$ \\
\hline \multicolumn{4}{|c|}{ e } \\
\hline 3.0 & 52 & $4.02 \pm 0.30$ & $3.21 \pm 0.38$ \\
\hline 3.5 & 56 & $4.45 \pm 0.09$ & $3.56 \pm 0.45$ \\
\hline 4.0 & 64 & $7.56 \pm 0.25$ & $3.87 \pm 0.05$ \\
\hline 4.5 & 48 & $3.87 \pm 0.20$ & $3.72 \pm 0.19$ \\
\hline 5.0 & 40 & $3.14 \pm 0.23$ & $3.82 \pm 0.52$ \\
\hline 5.5 & 36 & $2.69 \pm 0.31$ & $3.54 \pm 0.09$ \\
\hline 6.0 & 32 & $2.65 \pm 0.17$ & $3.68 \pm 0.33$ \\
\hline \multicolumn{4}{|l|}{ BAP+Kn } \\
\hline $2.0+1.5$ & 20 & $3.34 \pm 0.44$ & $3.00 \pm 0.40$ \\
\hline $2.0+2.0$ & 24 & $3.48 \pm 0.15$ & $3.35 \pm 0.27$ \\
\hline $2.0+2.5$ & 36 & $3.76 \pm 0.44$ & $3.63 \pm 0.20$ \\
\hline $3.0+1.5$ & 36 & $3.84 \pm 0.25$ & $3.92 \pm 0.43$ \\
\hline $3.0+2.0$ & 40 & $4.14 \pm 0.28$ & $4.90 \pm 0.35$ \\
\hline $3.0+2.5$ & 52 & $4.69 \pm 0.43$ & $4.83 \pm 0.36$ \\
\hline $4.0+1.5$ & 68 & $8.21 \pm 0.40$ & $5.43 \pm 0.22$ \\
\hline $4.0+2.0$ & 56 & $6.94 \pm 0.38$ & $5.12 \pm 0.08$ \\
\hline $4.0+2.5$ & 60 & $7.88 \pm 0.27$ & $5.33 \pm 0.31$ \\
\hline \multicolumn{4}{|l|}{ BAP+TDZ } \\
\hline $2.0+0.5$ & 63.33 & $11.43 \pm 0.36$ & $6.56 \pm 0.22$ \\
\hline $2.0+1.0$ & 76.67 & $16.58 \pm 0.24$ & $9.21 \pm 0.13$ \\
\hline $2.5+0.5$ & 60.00 & $9.42 \pm 0.16$ & $6.74 \pm 0.50$ \\
\hline $2.5+1.0$ & 66.67 & $12.78 \pm 0.53$ & $7.12 \pm 0.41$ \\
\hline $3.0+0.5$ & 56.67 & $9.33 \pm 0.09$ & $6.67 \pm 0.81$ \\
\hline $3.0+1.0$ & 70.00 & $12.17 \pm 0.67$ & $7.69 \pm 0.08$ \\
\hline $3.5+0.5$ & 56.67 & $9.20 \pm 0.65$ & $6.58 \pm 0.71$ \\
\hline $3.5+1.0$ & 60.00 & $9.06 \pm 0.58$ & $6.51 \pm 0.77$ \\
\hline \multicolumn{4}{|l|}{ BAP+TDZ+NAA } \\
\hline $2.0+1.0+0.5$ & 60.00 & $7.88 \pm 0.11$ & $3.68 \pm 0.70$ \\
\hline $2.0+1.0+1.0$ & 66.67 & $8.47 \pm 0.52$ & $4.12 \pm 0.17$ \\
\hline $2.0+1.5+0.5$ & 63.33 & $8.76 \pm 0.20$ & $4.56 \pm 0.06$ \\
\hline $2.0+1.5+1.0$ & 70.00 & $9.34 \pm 0.31$ & $4.67 \pm 0.45$ \\
\hline $3.0+1.0+0.5$ & 53.00 & $7.06 \pm 0.39$ & $3.60 \pm 0.81$ \\
\hline $3.0+1.0+1.0$ & 50.00 & $6.54 \pm 0.35$ & $3.38 \pm 0.32$ \\
\hline $3.0+1.5+0.5$ & 46.67 & $6.32 \pm 0.27$ & $3.47 \pm 0.18$ \\
\hline $3.0+1.5+1.0$ & 60.00 & $7.38 \pm 0.78$ & $3.82 \pm 0.67$ \\
\hline $4.0+1.0+0.5$ & 53.00 & $6.86 \pm 0.71$ & $3.55 \pm 0.58$ \\
\hline $4.0+1.0+1.0$ & 50.00 & $6.70 \pm 0.56$ & $3.89 \pm 0.22$ \\
\hline $4.0+1.5+0.5$ & 43.33 & $6.08 \pm 0.23$ & $3.37 \pm 0.83$ \\
\hline $4.0+1.5+1.0$ & 40.00 & $5.72 \pm 0.53$ & $2.94 \pm 0.44$ \\
\hline
\end{tabular}

In the present study, directly induced shoots were excised from nodal segments after 4 weeks of growth on initiation medium and cultured on MS gelled medium supplemented 
with different concentrations of BAP alone or in combination with TDZ, Kn and NAA. Among the different cytokinins BAP has been found the best cytokinin for shoot multiplication of B. bambos. The combined effect of BAP with another cytokinin such as TDZ and Kn, has been found to be more effective for axillary shoot multiplication of $B$. bambos than using BAP singly. In this regard, the effective combined concentration was $2.0 \mathrm{mg} / \mathrm{l} \mathrm{BAP}$ and $1.0 \mathrm{mg} / \mathrm{l} \mathrm{TDZ}$, which produced maximum (16.58 \pm 0.24$)$ average shoots per explant as well as maximum average shoot length $(9.21 \pm 0.13 \mathrm{~cm})$ in $B$. bambos (Table 3).

The shoot multiplication was best on MS medium supplemented with $3.0 \mathrm{mg} / \mathrm{l} \mathrm{BAP}$ in a previous study on B. bambos conducted by Arya and Sharma, (1998). These results were also supported by the earlier reports on micropropagation of bamboos, where BAP had been used extensively for shoot multiplication (Ramanayake et al., 2006; Yasodha et al., 2008; Ramanayake et al., 2008; Arya et al., 2008; Mudoi and Borthakur, 2009). TDZ has been proved an effective cytokinin for shoot proliferation in B. oldhamii (Lin et al., 2007); B. edulis (Lin and Chang, 1998); D. giganteous and B. vulgaris (Ramanayake et al., 2001 and 2006).

Combined effect of BAP, TDZ and NAA in shoot multiplication was also tested in the present study, in which a moderate multiplication rate of axillary shoots of B. bambos was found. There are some reports that addition of auxins (IAA or NAA) has either no effect on multiplication or decreased the multiplication of bamboo (Saxena, 1990; Das and Rout, 1991; Prutpongse and Gavinlertvatana, 1992).

A significant increase in the shoot multiplication rate with more healthy cultures was observed, when $10 \%$ coconut water and $4 \%$ sucrose was adjuvated with $2.0 \mathrm{mg} / \mathrm{l} \mathrm{BAP}$ and $1.0 \mathrm{mg} / \mathrm{l} \mathrm{TDZ}$, gave a maximum rate of multiplication with an average $26.7 \pm 0.60$ shoots per culture which were $11.2 \pm 0.32 \mathrm{~cm}$ long. The effect of coconut water on bamboo shoot multiplication has been reported by different authors. Nadgauda et al. (1990) and Rajapakse, (1992) induced shoot proliferation in the medium supplemented with coconut water in seedling derived culture of B. bambos and D. brandisii and in D. giganteus respectively, for which in vitro flower were also induced. Saxena and Bhojwani, (1993) reported to use $10 \%$ coconut milk (CM) as additive for better shoot proliferation in $D$. giganteus. Ramanayake et al. (2001) reported that a high level of sucrose (4\%) adversely affected the shoot multiplication in D. giganteus. 3\% sucrose are most commonly used by many workers as originally used by Murashige and Skoog (1962). Nadgir et al. (1984) and Brar, (2014) used 2\% sucrose for shoot multiplication in B. bambos as well as Yasodha et al. (2008) in B. nutans; Agnihotri et al. (2009) in D. hamiltonii and Nadha et al. (2013) in D. asper.

It was observed that rooting was more effectively induced when clusters of shoots (4-5) rather than individual shoot were used as also reported by Arya and Sharma, (1998) in $B$. bambos. Likewise, Sood et al. (1992); Bag et al. (2000); Agnihotri et al. (2009) and Nadha et al. (2013) in other bamboo species, Arya et al. (2012) in Dendrocalamus hamiltonii. 
In vitro rooting was attempted by transferring clusters (4-5) of shoots in a half-strength of both liquid and gelled MS medium fortified with different concentrations and combinations of auxins (IBA and NAA). A significant rooting was obtained within 15-22 days in $B$. bambos when $2.5 \mathrm{mg} / \mathrm{l} \mathrm{IBA}$ was added in conjunction with $2.5 \mathrm{mg} / \mathrm{l} \mathrm{NAA}$ with $86.67 \%$ rooting efficiency (Table 4) whereas, Arya and Arya, (2009) achieved 80-85\% rooting within 3-4 weeks of subculture on MS + 3.0 mg/l NAA and on MS + $10 \mathrm{mg} / \mathrm{l} \mathrm{IBA}$ in case of B. bambos.

Table 4. Effects of different concentrations of IBA alone or in combination with NAA in halfstrength of gelled MS medium on rooting of in vitro raised shoots of Bambusa bambos

\begin{tabular}{c|c|c|c}
\hline Auxins (mg/l) & \% of shoots rooted & $\begin{array}{c}\text { Average No. of } \\
\text { roots/propagule } \\
(\text { Mean } \pm \text { SE*) }\end{array}$ & $\begin{array}{c}\text { Average root } \\
\text { length }(\mathrm{cm}) \\
\text { (Mean } \pm \text { SE*) }\end{array}$ \\
\hline IBA & & & \\
1.5 & 6.67 & $1.00 \pm 0.00$ & $1.60 \pm 0.04$ \\
2.0 & 40.00 & $2.70 \pm 0.18$ & $2.63 \pm 0.39$ \\
2.5 & 26.67 & $4.83 \pm 1.42$ & $4.35 \pm 0.72$ \\
3.0 & 73.33 & $5.67 \pm 0.41$ & $4.89 \pm 0.57$ \\
IBA+NAA & & & \\
$1.5+1.5$ & 13.33 & $1.52 \pm 0.23$ & $1.82 \pm 0.31$ \\
$1.5+2.0$ & 26.67 & $1.86 \pm 0.12$ & $2.34 \pm 0.41$ \\
$1.5+2.5$ & 40.00 & $2.28 \pm 0.54$ & $2.57 \pm 0.28$ \\
$1.5+3.0$ & 46.67 & $2.43 \pm 0.55$ & $2.60 \pm 0.74$ \\
$2.0+1.5$ & 46.67 & $3.72 \pm 0.84$ & $2.95 \pm 0.57$ \\
$2.0+2.0$ & 53.33 & $3.88 \pm 0.64$ & $3.00 \pm 0.32$ \\
$2.0+2.5$ & 60.00 & $4.12 \pm 1.02$ & $3.44 \pm 0.60$ \\
$2.0+3.0$ & 66.67 & $4.34 \pm 1.21$ & $3.68 \pm 0.26$ \\
$2.5+1.5$ & 46.67 & $5.40 \pm 0.94$ & $4.47 \pm 0.14$ \\
$2.5+2.0$ & 66.67 & $5.61 \pm 0.52$ & $4.66 \pm 0.38$ \\
$\mathbf{2 . 5 + 2 . 5}$ & $\mathbf{8 6 . 6 7}$ & $\mathbf{8 . 7 2} \pm \mathbf{0 . 4 2}$ & $\mathbf{9 . 1 3} \pm \mathbf{0 . 2 0}$ \\
$2.5+3.0$ & 80.00 & $6.08 \pm 0.45$ & $7.11 \pm 0.13$ \\
$3.0+1.5$ & 60.00 & $5.16 \pm 0.25$ & $4.52 \pm 0.22$ \\
$3.0+2.0$ & 53.33 & $5.08 \pm 0.21$ & $4.66 \pm 0.46$ \\
$3.0+2.5$ & 40.00 & $4.75 \pm 0.35$ & $4.47 \pm 0.65$ \\
$3.0+3.0$ & 46.67 & $4.44 \pm 0.72$ & $4.84 \pm 0.30$ \\
\hline
\end{tabular}

$\mathrm{SE}^{*}=$ Standard error of mean.

However, 100\% rooting was observed by Singh et al. (2012b) in Dendrocalamus asper by using combination of $5 \mu \mathrm{M}$ of each of the IBA and NAA. The combined use of IBA and NAA for rooting was also reported by Islam and Rahman, (2005); Arya et al. (2006) and Rathore et al. (2009) in many important bamboo species.

In vitro raised plants need to be acclimatized before transferring them from in vitro condition to the field conditions, because they were grown under aseptic conditions with high humidity, diffused light and constant temperature. So, it is necessary to transfer the plants to field through various hardening stages to increase the survival percentage. 


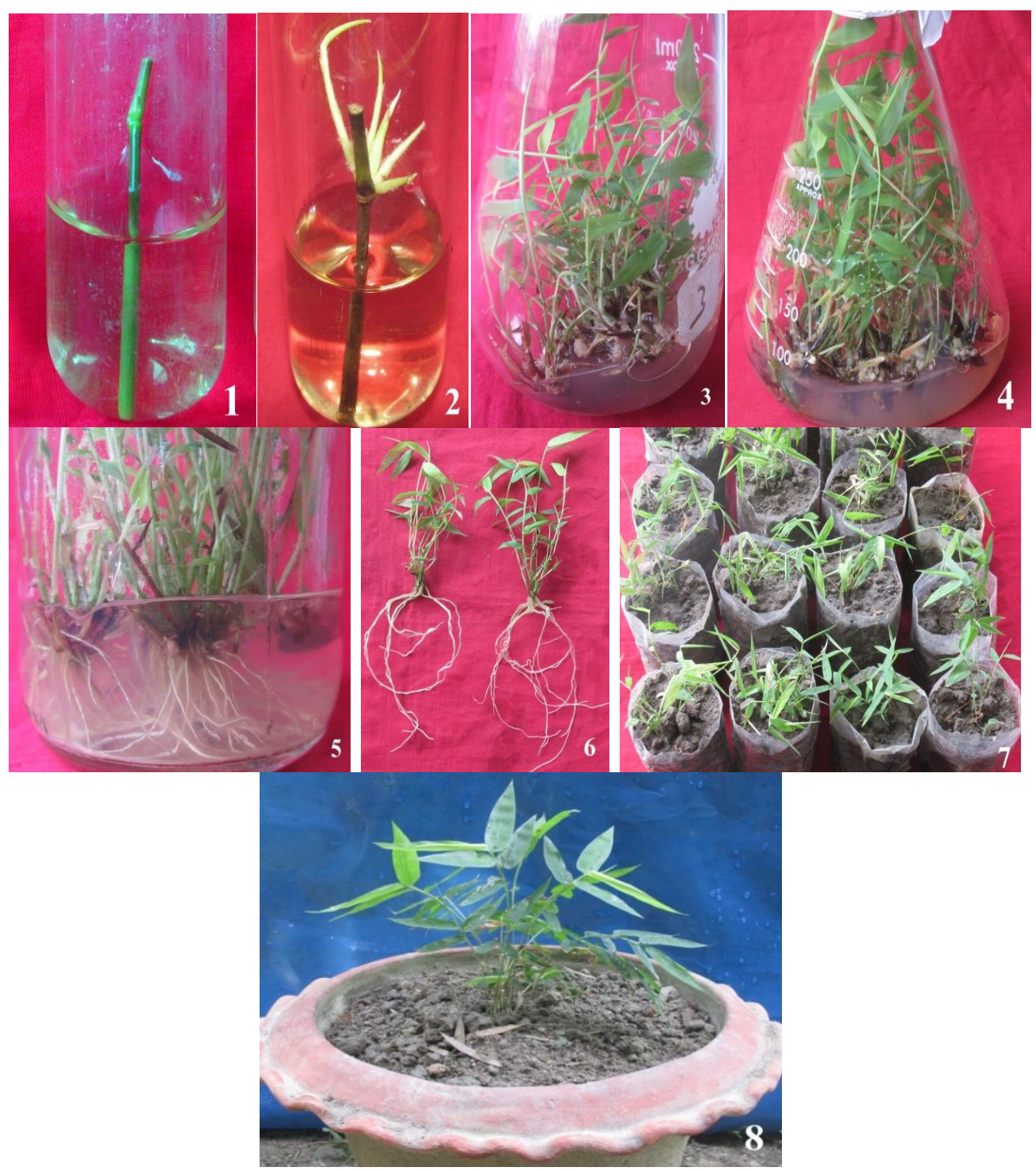

Plate 1-8: In vitro regeneration of Bambusa bambos (L.) Voss. 1. Surface sterilized nodal segments inoculate in MS liquid medium supplemented with $2.0 \mathrm{mg} / 1 \mathrm{BAP}+1.0 \mathrm{mg} / \mathrm{l}$ TDZ. 2. Direct shoot induction after 15 days of inoculation in MS liquid medium supplemented with $2.0 \mathrm{mg} / \mathrm{l} \mathrm{BAP}+1.0 \mathrm{mg} / \mathrm{l} \mathrm{TDZ}$. 3. Multiplication of shoots in the same gelled medium. 4. Rapid multiplication with elongated shoots in MS gelled medium supplemented with $2.0 \mathrm{mg} / \mathrm{l} \mathrm{BAP}+1.0 \mathrm{mg} / \mathrm{l} \mathrm{TDZ}+10 \% \mathrm{CW}+4 \%$ sucrose. 5. In vitro root induction on half-strength of gelled MS medium supplemented with $2.5 \mathrm{mg} / \mathrm{l} \mathrm{IBA}+2.5 \mathrm{mg} / \mathrm{l} \mathrm{NAA}$. 6. Complete plantlets. 7. Acclimatization of the regenerated plantlets in poly bags containing soil, sand and compost (1:1:1). 8 . Hardened plant in the larger pot containing garden soil and compost with $1: 1$ ratio (2 months). 
In this study, the rooted plantlets were acclimatized successfully with $100 \%$ survival to the soil condition. Arya and Sharma, (1998); Arya and Arya, (2009) and Anand et al., (2013) reported $80-90 \%$ survival rate by using the same soil mixture in case of $B$. bambos. Devi and Sharma, (2009) used the similar potting mixture in case of Arundinaria callosa and reported 60-70\% survival rate as well as Shood et al. (2014) in Phyllostachys pubescens with $77 \%$ survival rate, Arya et al. (2012) in D. hamiltonii, Mishra et al. (2011) in B. tulda, Brar et al. (2013) in D. membranaceus.

Finally the acclimatized plants, after a month, were transferred to the larger pots containing garden soil and compost with 1:1 ratio for sufficient growth and transplanted to the field. This micropropagation technique can be established as a practical method for high frequency plant regeneration of $B$. bambos at a faster rate than any conventional method of propagation.

The present study provides an efficient and cost effective protocol for in vitro propagation of Bambusa bambos (L.) Voss from the nodal segments of the field grown mature culm, with high multiplication efficiency, proper rooting and easy establishment in the field condition with normal growth performance of the in vitro propagated plants. This protocol will be helpful for large scale production of edible bamboo as well as for gene pool conservation.

\section{REFERENCES}

Agnihotri, R.K., Mishra, J. and Nandi, S.K. 2009. Improved in vitro shoot multiplication and rooting of Dendrocalamus hamiltonii Nees et Arn. Ex Munro: production of genetically uniform plants and field evaluation. Acta Physiologia Plant. 31: 961-967.

Alam, M.K. 1992. A note on the taxonomic problems, ecology and distribution of bamboos in Bangladesh. J. of Amer. Bamboo Soc. 9(1\&2): 1-7.

Anand, M., Brar, J. and Sood, A. 2013. In vitro propagation of an edible bamboo Bambusa bambos and assessment of clonal fidelity through molecular markers. Journal of Medical and Bioengineering. 2(4): 257-261.

Arya, I.D. and Arya, S. 2009. Propagation of bamboos through tissue culture technology and field plantation. $8^{\text {th }}$ World Bamboo Congress Proceedings. 6: 132-144.

Arya, I.D. and Arya, S. 2015. In vitro shoot Proliferation and Somatic Embryogenesis: Means of Rapid Bamboo multiplication. 10 ${ }^{\text {th }}$ World Bamboo Congress, Korea. Theme: Propagation, Plantations and Management.

Arya, I.D., Kaur, B. and Arya, S. 2012. Rapid and mass propagation of economically important bamboo Dendrocalamus hamiltonii. Indian Journal of Energy. 1(1): 11-16.

Arya, S. and Sharma, S. 1998. Micropropagation technology of Bambusa bambos through shoot proliferation. Indian Forester. 124: 725-731.

Arya, S., Rana, P.K., Sharma, R. and Arya, I.D. 2006. Tissue culture technology for multiplication of Dendrocalamus giganteus Munro. Indian Forester. 132(3): 345-357.

Arya, S., Satsangi, R. and Arya, I.D. 2008. Direct regeneration of shoots from immature inflorescences in Dendrocalamus asper (edible bamboo) leading to mass propagation. J. of Amer. Bamboo Soc. 21: 14-20. 
Banik, R.L. 1987. Techniques of bamboo propagation with special reference to pre-rooted and prerhizomed branch cuttings and tissue culture. In: Rao, A.N., Dhanarajan, G. and Sastry, C.B. (Eds.). Recent Research on Bamboos.Proceedings of International Bamboo Workshop, Hongshou, People's Republic of China, 1985, The Chinese Academy of Forestry, People'sRepublic of China and IDRC, Canada. pp. 160-169.

Bag, N., Chandra, S., Palni, L.M.S. and Nandi, S.K. 2000. Micropropagation of Dev-ringal [Thamnocalamus spathiflorus (Trin.) Munro]- a temperate bamboo, and comparison between in vitro propagated plants and seedlings. Plant Science. 156: 125-135.

Brar, J. 2014. Micropropagation of some edible bamboo species and molecular characterization of the regenerated plants. Ph.D. Thesis. Department of Biotechnology, Thapar University, Punjab, India.

Brar, J., Anand, M. and Sood, A. 2013. In vitro seed germination of economically important edible bamboo Dendrocalamus membranaceus Munro. Indian journal of experimental biology. 51: 88-96.

Chowdhury, P., Das, M., Sikdar, S.R. and Pal, A. 2004. Influence of the physiological age and position of the nodal explants on micropropagation of field-grown Dendrocalamus strictus Nees. Plant Cell Biotech. Mol. Biol. 5(1-2): 45-50.

Das, P. and Rout, G.R. 1991. Mass multiplication and flowering of bamboo in vitro. Orissa J. Hort. 19: 118-121.

Devi, W.S. and Sharma, G.J. 2009. In Vitro Propagation of Arundinaria callosa Munro- an Edible Bamboo from Nodal Explants of Mature Plants. The Open Plant Science Journal. 3: 35-39.

Islam, S.A.M.N. and Rahman, M.M. 2005. Micro-cloning in Commercially Important Six Bamboo Species for Mass Propagation and at a Large Scale Cultivation. Plant Tissue Cult. and Biotech. 15(2): 103-111.

Jha, A., Das, S. and Kumar, B. 2013. Micropropagation of Dendrocalamus hamiltonii through nodal explants. Global j. of bio-science and biotech. 2(4): 580-582.

Joshi, S.G. 2000. Medicinal Plants ( $1^{\text {st }}$ ed). Mohan Primlani Publications, New Delhi. pp. 314-15.

Kabade, A.U. 2009. Studies on refinement of protocols for rapid and mass in vitro clonal propagation, evaluation of genetic fidelity and growth performance of bamboo speciesBambusa bambos (L.) Voss and Dendrocalamus strictus (Roxb.) Nees. Ph. D. thesis. FRI University, Dehra Dun. pp. 198.

Kheng, T.C and Lee, C.C. 2011. Somatic embryogenesis from mature Bambusa ventricosa. College of Tropical Agriculture and Human Resources, University of Hawai'i, Manoa. BIO-11.

Liese, W. 1987. Research on Bamboo. Wood Science Technology. 21: 189-209.

Lin, C.S. and Chang, W.C. 1998. Micropropagation of Bambusa edulis through nodal explants of field-grown culms and flowering of regenerated plants. Plant Cell Reports. 17: 617-620.

Lin, C.S., Kalpana, K., Chang, W.C. and Lin, N.S. 2007. Improving multiple shoot proliferation in Bamboo Mosaic virus-free Bambusa oldhamii Munro propagation by liquid culture. Hort. Science. 42(5): 1243-1246.

Lin, C.S., Lin, C.C. and Chang, W.C. 2004. Effect of thidiazuron on vegetative tissue derived somatic embryogenesis and flowering of bamboo Bambusa edulis. Plant Cell Tissue and Organ Culture. 76: 75-82.

Mishra, Y., Patel, P. and Ansari, S.A. 2011. Acclimatization and macro proliferation of micropropagated plants of Bambusa tulda Roxb. Asian J. Exp. Biol. Sci. 2: 498-501.

Mudoi, K.D. and Borthakur, M. 2009. In vitro micropropagation of Bambusa balcooa Roxb. through nodal explants from field-grown culms and scope for up-scaling. Current Science. 96(7): $962-966$

Murashige, T. and Skoog, F. 1962. A revised medium for rapid growth and bioassays with tobacco tissue cultures. Physiology Plant. 15: 473-497. 
Nadgauda, R.S., Parasharami, V.A. and Mascarenhas, A.F. 1990. Precocious flowering and seeding behaviour in tissue-cultured bamboos. Nature. 344: 335-336.

Nadgir, A.L., Phadke, C.H., Gupta, P.K., Parasharami, V.A. and Mascarenhas, A.F. 1984. Rapid multiplication of bamboo by tissue culture. Silvae Genetica. 33(2): 219-223.

Nadha, H.K., Rahul, K., Sharma, R.K., Anand, M. and Sood, A. 2013. In vitro propagation of Dendrocalamus asper and testing the clonal fidelity using RAPD and ISSR markers. Int. J. of Curr. Research. 5(8): 2060-2067.

Nayak, S., Hatwar, B. and Jain, A. 2010. Effect of Cytokinin and Auxins on Meristem Culture of Bambusa arundinacea. Scholars Research Library, Der Pharmacia Lettre. 2(1): 408-414.

Prutpongse, P. and Gavinlertvatana P. 1992. In Vitro Micropropagation of 54 Species from 15 Genera of Bamboo. Hotr. Science. 27(5): 453-454.

Rajapakse, M.C. 1992. Studies on the in vitro development of Dendrocalamus giganteus. M. Phill. Thesis. Post Graduate, Institute of Agriculture, University of Peradeniya, Sri Lanka.

Ramanayake, S.M.S.D., Maddegoda, K.M.M.N., Vitharana, M.C. and Chaturani, G.D.G. 2008. Root induction in three species of bamboo with different rooting abilities. Sci. Hortic. 118: 270-273.

Ramanayake, S.M.S.D., Mermaduma, V.N. and Weerawardene, T.E. 2006. In vitro shoot proliferation and enhancement of rooting for the large scale propagation of yellow bamboo (Bambusa vulgaris 'Striata'). Scientia Horticulturae. 110: 109-113.

Ramanayake, S.M.S.D., Wanniarachchi, W.A.V.R. and Tennakoon, T.M.A. 2001. Axillary shoot proliferation and in vitro flowering in an adult giant bamboo, Dendrocalamus giganteus Wall. Ex Munro. In Vitro Cellular and Developmental Biology-Plant. 37: 667-671.

Rathore, T.S., Kabade, U., Jagadish, M.R., Somashekar, P.V. and Viswanath, S. 2009. Micropropagation and evaluation of growth performance of the selected industrially important bamboo species in southern India. $8^{\text {th }}$ World Bamboo Congress Proceedings. 6: 41-55.

Saxena, S. 1990. In vitro propagation of bamboo (Bambusa tulda Roxb.) through shoot proliferation. Plant Cell Reports. 9(8): 431-434.

Saxena, S. and Bhojwani, S.S. 1993. In Vitro clonal multiplication of four year old plants of the Bamboo Dendrocalamus longispathus Kurtz. In Vitro Cell Dev. Biol. 29: 135-142.

Sharma, P. and Sarma, K.P. 2011. In vitro propagation of Bambusa balcooa for a better environment. International Conference on Advances in Biotechnology and Pharmaceutical Sciences (ICABPS), Bangkok. pp. 248-252.

Sharma, P.K., Nath, S.K. and Murthy, N. 2014. Investigation on Fibre Characteristics of Dendrocalmus strictus and Bambusa bambos. Int. J. of Engineering Innovation \& Research. 3(3), ISSN: 2277-5668.

Shood, A., Nadha, H.K., Sood, S., Walia, S. and Parkash, O. 2014. Large scale propagation of an exotic edibal bamboo, Phyllostachys pubescens Mazel ex H. De Lehale (Moso Bamboo) using seeds. Indian Journal of Experimental Biology. 52: 755-758.

Singh, M., Jaiswal, U. and Jaiswal, V.S. 2000. Thidiazuron-induced in vitro flowering in Dendrocalamus strictus Nees. Current Science. 79: 1529-1530.

Singh, S.R., Dalal, S., Singh, R., Dhawan, A.K. and Kalia, R.K. 2012a. Evaluation of genetic fidelity of in vitro raised plants of Dendrocalamus asper \{Schult \& Schult. F. $\}$ Backer ex K. Heyne using DNA based markers. Acta Physiologiae Plantarum. 35(2): 419-430.

Singh, S.R., Dalal, S., Singh, R., Dhawan, A.K. and Kalia, R.K. 2012b. Micropropagation of Dendrocalamus asper \{Schult. \& Schult. F.\} Backer ex k. Heyne: an exotic edible bamboo. J. of Plant Bioche. and Biotech. 21(2): 220-228.

Sood, A., Sharma, O.P. and Palni, L.M.S. 1992. Improved methods of propagation of maggar bamboo (Dendrocalamus hamiltonii Nees et Arn. ex Munro) using single node cuttings taken from juvenile culms of elite seedlings. J. of Amre. Bamboo Soc. 9: 17-24. 
Waikhom, S.D. and Louis, B. 2014. An effective protocol for micropropagation of edible bamboo species (Bambusa tulda and Melocanna baccifera) through nodal culture. Hindawi Publishing Corporation. The Scientific World Journal. Article ID 345794. Pp. 8.

Yasodha, R., Kamala, S., Anand, K.S.P., Durai, K.P. and Kalaiarasi, K. 2008. Effect of glucose on in vitro rooting of mature plants of Bambusa nutans. Scientia Horticulture. 116: 113-116. 